\title{
JĘZYKOZNAWSTWO
}

\author{
ЛЮДМИЛА ФЕДОРОВА
}

\section{О модели русского словосложения с глагольной препозицией в сравнении с итальянской моделью}

\author{
On the model of Russian compounding with the verbal \\ preposition in comparison with the Italian model
}

\begin{abstract}
The paper is supposed to consider the formation of Russian compounds based on the imperative construction in comparison with a similar model in Italian. It is believed that in literary Russian this model is not productive, although it occurs in a limited number of examples: for the evaluative names of persons (sorvigolova 'daredevil'), for the names of animals and plants (vertišejka, perekati-pole) and in some other cases. However, in Romance languages, and particularly in Italian, this is one of the most productive models, although its grammatical status is not usually associated with the imperative construction. As for Russian, it is possible to assume a transformation of the imperative sentences and imperative meaning, and only a particular modal shade of typical actions is preserved. The model itself is represented as a transition from incomplete compounding to the canonical productive model with an interfix. The results of an experiment on the translation of Italian compounds into Russian nonce compounds show a number of transitional cases, supporting this hypothesis.
\end{abstract}

Keywords: Russian compounding, imperative model, comparison with the Italian model, nonce compounds

Людмила Федорова, Российский государственный гуманитарный университет, Москва Россия, lfvoux@yandex.ru, ORCID ID: https://orcid.org/0000-0002-2284-6643

\section{Введение и общая проблематика статьи}

В работе предполагается рассмотреть образование сложных слов в русском языке по модели $(\mathrm{V}-\mathrm{N})_{\mathrm{N}}($ сорвиголова, перекати-поле) в сравнении с итальянской сходной моделью. Особенностью этой модели является глагольная форма императива в первой позиции. Считается, что в русском литературном языке данная модель не обладает продуктивностью, однако в романских 
языках, в частности в итальянском, модель с препозицией глагола - одна из самых продуктивных, хотя ее грамматический статус остается спорным.

Выбор материала итальянского языка для сравнения обусловлен, с одной стороны, распространенностью модели в итальянском языке, с другой интересом итальянских лингвистов к проблемам типологии словосложения и русского словосложения (Benigni, Masini; Scalise, Bisetto и др.).

Для русского языка можно предположить развитие данной модели преобразованием императивных фраз, причем побудительное значение императива стирается, сохраняя лишь особый модальный оттенок типичного действия. Сама модель представляется переходной от неполного сложения к канонической продуктивной модели с соединительной гласной. Результаты эксперимента по переводу итальянских сложных слов русскими окказионализмами показывают ряд переходных случаев, поддерживая данную гипотезу.

\section{Предшествующие исследования}

Модель с препозицией глагола $(\mathrm{V}-\mathrm{N})_{\mathrm{N}}$ широко распространена в романских языках - в итальянском (spazzacamino - трубочист, 'мести + труба', copriletto - покрывало, 'покрывать + кровать'), во французском (casse-coeur - сердцеед, 'разбить + сердце', garde-fou - перила, 'беречь + дурак'), в испанском (arrancapinos - коротышка, 'вырвать + сосны', lavaplatos - посудомоечная машина, 'мыть + тарелки').

Проблема определения грамматической природы данной модели сложных слов давно обсуждается в лингвистике (Darmesteter; Scalise; Scalise, Bisetto; Chung; Villoing; Rosenberg; Arutûnova 1956, 2007; Fedorova 2007, 2012). Сложность в том, что первый глагольный компонент в романских языках имеет омонимичную форму, т. е. позволяет предполагать индикатив, императив или просто недифференцированную глагольную основу. А значение чаще всего не позволяет сделать однозначный выбор между предписывающим или описательным. Еще в 1874 г. Арсен Дармстетер (Darmesteter) предположил, что подобные слова происходят из императивных фраз, в которых глагольный компонент постепенно утратил отчетливый императивный характер. Эту точку зрения поддерживает Нина Арутюнова, исследовавшая данную модель в испанском языке (Arutûnova $1956,2007)$. Она считает, что изначально глагольная форма в ней имела императивный характер, но в настоящее время побудительный смысл не улавливается, и в толкованиях используются описательные конструкции (тот, кто...). 
Итальянские исследователи исходят преимущественно из современного значения слов. Серджо Скализе (Scalise) анализирует грамматическую природу итальянских композитов. Основы глаголов в композитах принадлежат разным спряжениям:

1-е спр. portalettere - почтальон, lui porta lettere - 'он носит письма';

2-е спр.: accendicigari - зажигалка, lui accende cigari - 'она зажигает сигареты';

3-е спр.: copriletto - покрывало, lui copri letto - 'оно покрывает кровать'.

Скализе рассматривает 3 возможные грамматические интерпретации глагольного компонента: 1) форма индикатива 3 л. ед. ч.; 2) форма императива 2 л. ед. ч.; 3) нейтральная глагольная основа - корень с тематическим гласным. В первой интерпретации, соответствующей описательной конструкции ('тот, кто...'), отсутствует объяснение для смены тематического гласного -e на $\boldsymbol{- i}$ у глаголов 2-го спряжения (accende - accendi-); то же касается и третьей интерпретации (с тематическим гласным). Естественно объяснить эти формы как императив (- $\boldsymbol{a}$ - его грамматический показатель для глаголов 1-го спряжения, $-\boldsymbol{i}$ для 2-го и 3-го спряжения). Но этому препятствует семантика: здесь нет никакого признака 'повелительности'. Скализе склонен считать, что в этих формах использована нейтральная основа с тематическим гласным, поскольку и значение 'изъявительности' (индикатива) также отсутствует. Перемена тематического гласного во 2-м спряжении остается без объяснения. Хотя точка зрения Скализе наиболее принята в итальянской грамматике, она не представляется единственно возможной и вполне оправданной.

По-видимому, эта же модель присутствует в английском: cutthroat - головорез, 'резать + горло', daredevil - смельчак, сорвиголова, 'вызвать + дьявол'; killjoy - зануда, 'убить + радость' и др. Но здесь еще больше возможностей для грамматической омонимии.

Иное наблюдается в русском языке. Здесь нет вопроса о грамматической омонимии: по форме глагольный компонент однозначно соответствует императиву: перекати-поле, гуляй-город, сорвиголова. Однако побудительное значение не улавливается. Русская грамматика-80 (Švedova 246-247) квалифицирует эту особенность глагольной основы лишь как совпадение по форме с императивом. Но возможно предположить, что побудительное значение существовало в исходной номинации, которая представляла собой обращение к лицу или персонифицированному предмету с неким призывом, провокативным или шутливым. Такими представляются, в частности, украинские фамилии и прозвища, построенные по данной модели: Майборода, Куйбеда, Потушисвечка, Непийвода, Вершигора, Вырвидуб, Давимуха и проч. Шутливо-хвалебный или бранный смысл большинства подобных 
наименований показывает их не книжный, а исконно разговорный, карнавальный (по Михаилу Бахтину) характер, присущий народной смеховой культуре: „Все подлинные прозвища амбивалентны, то есть носят хвалебно-бранный оттенок” и далее: „Образование собственных имен по типу ругательств является наиболее распространенным способом как у Рабле, так и вообще в народной комике" (Bahtin 508-509). Эти номинации представляется не вполне оторвавшимися от самой ситуации речи, в которой они могли бы быть окказиональными высказываниями, обращенными к собеседнику и содержащими побуждение. Можно сравнить календарные наименования, устроенные подобным образом: Афанасий-ломонос - береги нос! (31 января); Емельяны, накрути бураны (неделя 21-28 января). В дальнейшем при свертывании высказывания в однословную структуру императивные формы начинают восприниматься как характеризующие референта по необходимому, типичному действию субъекта или объекта, что и является основой описательной конструкции. Тем самым побудительное значение императива размывается, уступая более широкому модальному значению (подробнее см. Fedorova 2008).

Аналогичные образования имеются и в других славянских языках: в польском (chwalipięta - хвастун, 'хвалить + пятка', męczydusza - зануда, 'мучить + душа'), в чешском (lamželezo - силач, ‘ломать + железо’, prídržtaška, podržtaška - ассистент 'подержать + сумка'); в болгарском (лапнимуха - ротозей, 'проглотить + муха', вариклечко - скряга, 'варить + щепка'). Для них характерна ироническая экспрессия и разговорный, нередко сниженный характер (Fedorova 2007).

По сравнению с канонической моделью сложного слова с соединительной гласной (типа $\left.(\mathrm{N}-\mathrm{o} / \mathrm{e}-\mathrm{V})_{\mathrm{N}}\right)$ императивная модель $(\mathrm{V}-\mathrm{N})_{\mathrm{N}}$ представляется промежуточным, незавершенным образованием: первый глагольный компонент сохраняет исходную форму, а вторая основа, восходящая обычно к падежной форме существительного, подвергается унификации, так чтобы целое могло встроиться в парадигму существительного (при этом может изменяться грамматический класс: ср. болиголов, но сорвиголова). Иногда происходит и унификация по соединительной гласной, т. е. показатель императива заменяется на -о-/-е-, ср. вертопрах и вертишейка, но сохранятся особый порядок компонентов $(\mathrm{V}-\mathrm{o} / \mathrm{e}-\mathrm{N})_{\mathrm{N}}$, ср.: вертопрах и уховёртка, скалозуб и зубоскал, а также щелкопёр ('щёлкай пером'), лежебока, ломонос.

Как переход от высказывания к сложному слову можно рассматривать случаи сращений: не-тронь-меня, Мойдодыр. В них кроме императива присутствуют грамматические показатели косвенных форм и служебные показатели, что отличает их от рассматриваемой императивной модели. Таким образом, сращения оказываются как бы кристаллизованными высказыва- 
ниями, цитатами, лишенными предикативности и превратившимися в самостоятельную номинацию. Таковыми являются, по-видимому, итальянские примеры композитов на основе императивных повторов типа il sorre-sorre (Sorre! Sorre! 'сомкни ряды' - восклицание в детской игре - дало название самой игре), которые рассматривает Анна Торнтон (Thornthon).

В отличие от сращений императивные композиты оказываются морфологически оформленной конструкцией. При этом в русском языке они сохраняют большей частью разговорный характер, появляясь в игровых номинациях, напр., Читай-город, ВырвиЗуб, Бериложка, СтройДом. Иногда композиты этого типа используются в атрибутивной функции, передавая оценочные характеристики: друзья неразлейвода, блондинка вырвиглаз.

Таким образом, рассматриваемая модель, отмеченная во многих языках в основном для разговорных номинаций, не имеет однозначной грамматической интерпретации. Вопрос о ее продуктивности для русского языка остается малоизученным.

\section{Эксперимент}

Целью эксперимента было оценить продуктивность императивной модели в русском языке, основываясь на способности носителей языка к порождению окказиональных номинаций с заданным смыслом. Эксперимент проводился в два этапа. На первом этапе респондентам (студенты гуманитарных вузов РГГУ и ВШЭ Москвы) были предложены 10 итальянских сложных слов модели $(\mathrm{V}-\mathrm{N})_{\mathrm{N}}$ и аналогичной $(\mathrm{V}-\text { Pron) })_{\mathrm{N}}$, для которых были даны значения компонентов. В задании требовалось предложить свой перевод сложным словом, не существующим в русском языке, но передающим достаточно точно смысл итальянского слова и понятным для носителей русского языка.

Таблица 1. Список итальянских композитов, использованных в эксперименте

\begin{tabular}{|l|l|l|l|}
\hline \multicolumn{1}{|c|}{ Композит } & \multicolumn{1}{|c|}{ Компоненты (ит.) } & \multicolumn{1}{|c|}{ Компоненты (рус.) } & \multicolumn{1}{|c|}{ Значение } \\
\hline 1. lustrascarpe & $\begin{array}{l}\text { lustrare } \\
\text { scarpe }\end{array}$ & $\begin{array}{l}\text { чистить } \\
\text { ботинки/башмаки/ } \\
\text { туфли }\end{array}$ & чистильщик обуви \\
\hline 2. rompicollo & $\begin{array}{l}\text { rompere } \\
\text { collo }\end{array}$ & $\begin{array}{l}\text { сломать } \\
\text { шея }\end{array}$ & смельчак/трюкач \\
\hline 3. guardaboschi & $\begin{array}{l}\text { guardare } \\
\text { boschi }\end{array}$ & $\begin{array}{l}\text { смотреть/охранять } \\
\text { леса }\end{array}$ & лесник \\
\hline 4. mangiafuoco & $\begin{array}{l}\text { mangiare } \\
\text { fuoco }\end{array}$ & $\begin{array}{l}\text { есть/пожирать } \\
\text { огонь/пламя }\end{array}$ & бахвал \\
\hline
\end{tabular}


Людмила Федорова

\begin{tabular}{|c|l|l|l|}
\hline 5. piantagrane & $\begin{array}{l}\text { piantare } \\
\text { grane }\end{array}$ & $\begin{array}{l}\text { сажать/растить } \\
\text { неприятности/беды } \\
\text { (букв. крупа/зёрна) }\end{array}$ & придира/зануда \\
\hline 6. portachiavi & $\begin{array}{l}\text { portare } \\
\text { chiavi }\end{array}$ & $\begin{array}{l}\text { носить } \\
\text { ключи }\end{array}$ & брелок для ключей \\
\hline 7. asciugacapelli & $\begin{array}{l}\text { asciugare } \\
\text { capelli }\end{array}$ & $\begin{array}{l}\text { сушить/вытирать } \\
\text { волосы }\end{array}$ & фен \\
\hline 8. asciugamani & $\begin{array}{l}\text { asciugare } \\
\text { mani }\end{array}$ & $\begin{array}{l}\text { сушить/вытирать } \\
\text { руки }\end{array}$ & полотенце \\
\hline 9. tritatutto & $\begin{array}{l}\text { tritare } \\
\text { tutto }\end{array}$ & $\begin{array}{l}\text { измельчать/крошить } \\
\text { всё }\end{array}$ & кухонный комбайн \\
\hline 10. scolapasta & $\begin{array}{l}\text { scolare } \\
\text { pasta }\end{array}$ & $\begin{array}{l}\text { сливать } \\
\text { паста/макароны }\end{array}$ & дуршлаг \\
\hline
\end{tabular}

На первом этапе группа респондентов из 65 человек предложила свои варианты перевода - 661 слово в общей сумме, с исключением не соответствующих условию, т. е. уже существующих в языке или не являющихся сложными. После исключения повторов получилось всего 272 разных слова. На втором этапе другая группа респондентов (40 человек) оценивала предложенные переводы, выделив наиболее удачные. На основе анализа порождения и восприятия окказионализмов мы могли бы получить информацию об относительной продуктивности императивной модели в русском языке.

В результате первой серии эксперимента были получены сложные слова четырех разных моделей: 1) чистого сложения (лесоохранник), 2) с так называемым нулевым суффиксом $(\mathrm{N}-\mathrm{V})_{\mathrm{N}}($ туфлечист) - их для удобства можно назвать бессуффиксальными, 3) суффиксально-сложной модели с различными суффиксами $(\mathrm{N}-\mathrm{V} \text {-suf) })_{\mathrm{N}}$ (ключеноска), 4) императивной модели $(\mathrm{V}-\mathrm{N})_{\mathrm{N}}$ (сломишей, чистибот).

Надо отметить, что композиты чистого сложения в качестве второго компонента обычно содержат суффиксальное слово, так что при формальном анализе их бывает трудно отличить от слов суффиксально-сложной модели. Критерием отнесения слова к суффиксально-сложной модели является отсутствие в языке второго компонента в качестве самостоятельного слова или же использование его в другом значении. Так, в слове ключеноска компонент -носка не является самостоятельным словом с предметным значением. Модель с нулевым суффиксом тоже может считаться суффиксально-сложной, однако в ее трактовке нет полного единодушия; так, есть и точка зрения, квалифицирующая такие образования как сложно-флексийные (т. е. флексия рассматривается и как словообразовательный формант, см. Nemčenko); для формального анализа эту модель удобнее выделить отдельно. Встречались в ответах и бессуффиксальные образования с обратным порядком компо- 
нентов $(\mathrm{V}-\mathrm{o} / \mathrm{e}-\mathrm{N})_{\mathrm{N}}$, не характерные для русского языка (растобед, ср. вертоnрax).

Результаты статистического анализа показывают, что респонденты предпочли конструкции с суффиксами: их выбрали в 52\% переводов; бессуффиксальные конструкции использовали в 43,3\% случаев; императивные в 4,7\% случаев. Однако если сравнивать конкретные модели, то бессуффиксальная модель превосходит любую другую с конкретным суффиксом: для $(\mathrm{N}-\mathrm{V})_{\mathrm{N}}-$ $40,8 \%$ (для $\left.(\mathrm{V}-\mathrm{N})_{\mathrm{N}}-2,5 \%\right)$, для образований с суффиксом -тель $-21,6 \%$, для -кa - 13,3\% (для остальных суффиксов показатели ниже). Результаты первого этапа эксперимента подробно описаны в отдельной работе (см. Fedorova, Naccarato).

В таблице 2 приводятся сопоставительные данные анализа по двум сериям эксперимента. Выделены три наиболее частотных примера перевода каждого композита и три, признанные большинством наиболее удачными.

Таблица 2. Результаты двух серий эксперимента

\begin{tabular}{|c|c|c|}
\hline Композит (ит.) & $\begin{array}{c}\text { Самые частые переводы на } \\
\text { русский }\end{array}$ & Оценены как наиболее удачные \\
\hline 1. lustrascarpe & $\begin{array}{l}\text { туфлечист (20)* } \\
\text { обувечистильщик (10) } \\
\text { башма/очист (8) }\end{array}$ & $\begin{array}{l}\text { туфлечист (13) } \\
\text { башма/очист** (12) } \\
\text { ботинкочист (11) }\end{array}$ \\
\hline 2. rompicollo & $\begin{array}{l}\text { шеелом (29) } \\
\text { сломо/а/ишей (5) } \\
\text { сломо/ашея (3) }\end{array}$ & $\begin{array}{l}\text { шеелом (17) } \\
\text { сломо/а/ишей (10) } \\
\text { шеесвёрт (8) }\end{array}$ \\
\hline 3. guardaboschi & $\begin{array}{l}\text { лесо(о)хранник (16) } \\
\text { лесо(о)хранитель (13) } \\
\text { лесосмотритель (11) }\end{array}$ & $\begin{array}{l}\text { лесо(о)хранник (18) } \\
\text { лесо(о)хранитель (17) } \\
\text { лесосмотритель (17) }\end{array}$ \\
\hline 4. mangiafuoco & $\begin{array}{l}\text { огнеед (13) } \\
\text { огнежё/оp } 12 \\
\text { пламе/яед (10) }\end{array}$ & $\begin{array}{l}\text { огнеед (16) } \\
\text { пламе/яед (12) } \\
\text { огнежё/оp (8) }\end{array}$ \\
\hline 5. piantagrane & $\begin{array}{l}\text { бедораститель (5) } \\
\text { бедосад (5) } \\
\text { растобед (5) }\end{array}$ & $\begin{array}{l}\text { бедосей/в (15) } \\
\text { скукоплод (8) } \\
\text { сейбеда (3) }\end{array}$ \\
\hline 6. portachiavi & $\begin{array}{l}\text { ключеноска (33) } \\
\text { ключенос (19) } \\
\text { ключеноситель (4) }\end{array}$ & $\begin{array}{l}\text { ключеноска (15) } \\
\text { ключедержатель (10) } \\
\text { ключеносец (3) }\end{array}$ \\
\hline 7. asciugacapelli & $\begin{array}{l}\text { волососушка (14) } \\
\text { волососушитель (10) } \\
\text { волососушилка (8) } \\
\end{array}$ & $\begin{array}{l}\text { волососушитель (15) } \\
\text { волосушилка (8) } \\
\text { головосушка (8) }\end{array}$ \\
\hline 8. asciugamani & $\begin{array}{l}\text { рукосушка (16) } \\
\text { руковытиралка (8) } \\
\text { рукосушитель (5) } \\
\text { рукотё/ир (5) }\end{array}$ & $\begin{array}{l}\text { рукосушка (11) } \\
\text { руковытиратель (9) } \\
\text { рукосушитель (9) } \\
\text { рукотёр (6) }\end{array}$ \\
\hline
\end{tabular}




\begin{tabular}{|l|l|l|}
\hline 9. tritatutto & $\begin{array}{l}\text { всекрошитель (18) } \\
\text { всеизмельчитель (7) } \\
\text { всемельчитель (5) }\end{array}$ & $\begin{array}{l}\text { всекрошитель (8) } \\
\text { всёизмельчитель (6) } \\
\text { всерезка (6) }\end{array}$ \\
\hline 10. scolapasta & пасто/аслив (22) & пасто/аслив (11) \\
& пастосливатель (5) & макаронослив (7) \\
& плейвода (5) \\
& макароносливатель (4)
\end{tabular}

* В скобках после слова указано количество примеров.

** В скобках внутри слова дается вариант ответа с дополнительной буквой.

Можно заметить, что не все предложенные переводы соответствуют правилам образования сложных слов; некоторые показывают колебания в выборе основы (рукотёр - рукотир, бедосей - бедосев), в других наблюдаются варианты написания соединительной гласной (пастослив - пастаслив). Эта вариативность говорит о трудности процесса словосложения.

Для слов, обозначающих лицо (агенса), при переводе чаще выбираются бессуффиксальные модели, в то время как для обозначения предметов (инструментов) чаще суффиксальные образования. При этом можно заметить, что в обозначениях лица суффиксальные переводы относятся в большинстве случаев к чистому сложению (обувечистильщик, лесоохранник). Но при оценке наиболее удачных переводов для обозначения лица предпочтение отдается бессуффиксальным композитам.

Как более удачные в целом оцениваются более краткие слова, часто это слова бессуффиксальной модели. Стремление к лаконизму фонетической формы нередко приводит к усечению основ: бамма/очист, волосушка. При выборе второй основы можно предположить аналогию, точнее - ориентацию на существующие слова с аналогичной опорной основой (башмачист - трубочист, огнеед - людоед и др.).

Слова императивной модели предлагались в переводах каждого слова, хотя иногда с ошибками, однако по частоте они уступали другим моделям. Так, были предложены композиты: сломишей, сейбеда, расти-беда, носиключ, сушиголов, суширук, крошивсё, слейвода. Кроме того, нередко наблюдались промежуточные формы бессуффиксальной модели с обратным порядком компонентов $(\mathrm{V}-\mathrm{o} / \mathrm{e}-\mathrm{N})_{\mathrm{N}}$ : чистебот, смотролес, растобед, но возможно, за этим стоит неудачная попытка построить „правильное” сложное слово.

Наиболее частотными примерами императивной модели оказались переводы ит. rompicollo, на выбор которых, вероятно, влияло существование в русском языке синонима сорвиголова, построенного по императивной модели (его часто предлагали в переводах, но мы отсеяли такие переводы как не соответствующие условию оригинальности). 
В переводах rompicollo обнаруживается целый ряд вариативных образований:

(1) сломи-шею

(2) сломайшея

(3) сломашей

(4) сломишей

(5) сломишея

(6) сломошей

(7) ломошей

Здесь возможны две интерпретации. Во-первых, эти примеры могут отражать попытки построить „императивный” композит (сломайшея, сломишей), либо с усечением глагольного - ай до - $a$, либо, как результат гиперкоррекции, с соединительной гласной -o-/-e- по аналогии с классической моделью сложного слова. Во-вторых, слова действительно могли строить-

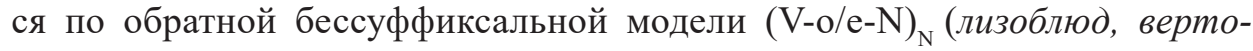
npax), которая хоть и ограниченно, все же встречается в русском языке как параллельная образованиям по модели $(\mathrm{A}-\mathrm{O} / \mathrm{e}-\mathrm{N})_{\mathrm{N}}$ (чистотел, тяжеловес) (Švedova 252).

В пользу первой интерепретации говорит то, что написаний с ошибкой в соединительной гласной встречается достаточно много и в других словах (чаще всего -a/-я- вместо -о-/-е-, напр., шеялом, рукасушка, пастаслив или -е- с гиперкоррекцией вместо -и-: чистебот, сушеволос). Вторая интерпретация - ориентация на обратную бессуффиксальную модель (лизоблюд) представляется менее убедительной, поскольку, хотя примеры типа лизоблюд достаточно редки в языке, их маргинальность не осознается в силу обычного оформления с соединительной гласной.

Однако возможно посмотреть на предложенные формы как переходные между императивным словосочетанием и классической моделью сложного слова $(\mathrm{N}-\mathrm{o} / \mathrm{e}-\mathrm{V})_{\mathrm{N}}$, тогда императивная модель $\left(\mathrm{V}_{\mathrm{imp}}-\mathrm{N}\right)_{\mathrm{N}}$, как и обратная бессуффиксальная $(\mathrm{V}-\mathrm{o} / \mathrm{e}-\mathrm{N})_{\mathrm{N}}$, представляются промежуточными фазами незавершенного словосложения. При этом разные варианты перевода отражают этапы преобразования, сворачивания словосочетания в сложное слово: сломи шею - сломишея - сломишей - сломошей - ломошей - шеелом или: сломай шею - сломайшея - сломашей - сломошей - ломошей - шеелом. Сначала при сращении выравнивается опорная основа, далее преобразуется соединительный формант: усечение -й императивной формы глагола упрощает переход к модели с соединительной гласной.

При такой интерпретации результаты эксперимента в известном смысле коррелируют с представлением о диахроническом переходе от аналитической структуры словосочетания к синтетической модели сложного слова. 


\section{Заключительные замечания}

В результате проведенного эксперимента были получены данные об относительной продуктивности моделей словосложения в русском языке. Императивная модель обладает меньшей продуктивностью по сравнению с бессуффиксальной и суффиксально-сложной моделями. Однако в ряде случаев она может конкурировать с более распространенными моделями, что показывает оценка наиболее удачных образований сломишей, сейбеда, слейвода.

Императивную модель можно рассматривать как промежуточную при переходе от императивной конструкции к каноническому сложному слову (от синтаксической к морфологической конструкции); здесь сохраняется форма первой основы, но унифицируется вторая. Однако эта промежуточная модель все же имеет закрепленность в разговорном языке.

Если случаи сращения и обратной императивной модели в языке в целом единичны, то императивная модель предоставляет более широкие возможности как в экспрессивном, так и в морфологическом отношении (в использовании приставочных глаголов), создавая яркие образы номинации, поэтому слова этой модели сохраняются и вновь образуются в разговорной речи.

\section{Библиография}

Arutûnova, Nina. Problemy morfologii i slovoobrazovaniâ (na materiale ispanskogo âzyka). Moskva, ÂSK, 2007.

Arutûnova, Nina. „Složnye imena suŝestvitel'nye tipa el guardabosque v sovremennom ispanskom âzyke". Institut âzykoznaniâ. Doklady i soobŝeniâ. X. Moskva, Izdatel'stvo Akademii nauk SSSR, 1956.

Bahtin, Mihail. Tvorčestvo Fransua Rable i narodnaâ kul'tura srednevekov'â i renessansa. Moskva, Hudožestvennaâ literatura, 1990.

Benigni, Valentina, Francesca Masini. „Compounds in Russian”. Lingue e Linguaggio, nr 8 (2), 2009, s. 171-193.

Chung, Karen Steffen. „V+N Function-Describing Compounds”. Bulletin of the College of Liberal Arts. National Taiwan University, nr 41, 1994, s. 181-221.

Darmesteter, Arsène. Traité de la formation des mots composés dans la langue française, comparée aux autres langues romanes et au latin. Paris, Librairie A. Franck, 1874.

Fedorova, Lûdmila. „Malen'kie komedii složnyh slov”. Logičeskij analiz âzyka. Âzykovye mehanizmy komizma. Red. Nina Davidovna Arutûnova. Moskva, RAN IÂ, 2007, s. 699-711.

Fedorova, Lûdmila. „O smehovoj prirode modeli složnyh slov-prozviŝ v slavânskih i romanskih âzykah". Vostocnoslavânskie âzyki i literatury v istoriceskom i kul'turnom kontekstah: kognitivnaâ lingvistika i konceptual'nye issledovaniâ. Red. Marina Pimenova. Kiev, IÂ im. Potebni NAN Ukrainy, 2012, s. 380-387. 
Fedorova, Lûdmila, Chiara Nakkarato. „Okkazional'noe slovosloženie v russkom âzyke: produktivnost' i analogiâ". Studi di linguistica slava. Nuove prospettive e metodologie di ricerca./Studie ricerche - 20. Edizioni Ca' Foscari. Digital Publishing, 2019, s. 155-173.

Nemčenko, Vasilij. Sovremennyj russkij âzyk. Slovoobrazovanie. Moskva, Vysšaâ škola, 1984.

Rosenberg, Maria. La formation agentive en français: les composés $[V N / A / A d v / P]_{N / A}$ et les dérivés $V$-ant, V-eur et V-oir(e). Stockholms universitet, Doktorsavhandling, 2008.

Scalise, Sergio. Morfologia. Bologna, Il Mulino, 1994.

Scalise, Sergio, Antonietta Bisetto. „The Classification of Compounds”. The Oxford Handbook of Compounding. Red. Rochelle Lieber, Pavol Stekauer. New York, Oxford University Press, 2009.

Švedova, Natal'â, red. Russkaâ grammatika. T. I. Moskva, Nauka, 1980.

Thornton, Anna. „Italian verb reduplication between syntax and the lexicon”. Rivista di Linguistica, nr 21 (1), 2009, s. 235-261.

Villoing, Florence. „Les mots composés VN du français: argument en faveur d'une construction morphologique". Cahiers de Grammaire, Morphologie et Lexique, nr 28, 2002, s. 183-196. 
